\title{
Determination of the Optical Properties of Basal Cancer Using OCT System
}

\author{
Sohad Elwakeel ${ }^{1}$, Nafie Almuslet ${ }^{1}$, Yahia Badr Aldeen ${ }^{2}$, Khalid Haroun ${ }^{3}$ \\ ${ }^{1}$ Institute of Laser, Sudan University of Science and Technology, Khartoum, Sudan \\ ${ }^{2}$ National Institute of Laser Enhanced Science, Cairo University, Cairo, Egypt \\ ${ }^{3}$ Facility of Radiobiological and Imagine Science, Alzaaim Alazahari University, Khartoum, Sudan \\ Email: *sohadelwakeel@gmail.com,mnmfa2008@yahoo.com, ybeldeen @hotmail.com, khalmai@hotmail.com
}

How to cite this paper: Elwakeel, S., Almuslet, N., Aldeen, Y.B. and Haroun, K. (2019) Determination of the Optical Properties of Basal Cancer Using OCT System. Open Journal of Biophysics, 9, 88-97. https://doi.org/10.4236/ojbiphy.2019.92007

Received: December 30, 2018

Accepted: February 24, 2019

Published: February 27, 2019

Copyright $\odot 2019$ by author(s) and Scientific Research Publishing Inc. This work is licensed under the Creative Commons Attribution International License (CC BY 4.0).

http://creativecommons.org/licenses/by/4.0/

\begin{abstract}
The objective of this work is to determinate the optical properties of basal cancer cells using an optical coherence tomography (OCT). OCT system with He-Ne \& diode laser was used to make interference pattern for the basal cancer, then the output was displayed by optical detector, information of an electrical signal passed to the digital oscilloscope to give the object information after Fourier transform processing for that signal, then PC and CCD were used to display FFT signal. Finally many steps were done to determine the optical properties for the basal cancer. The intensity of the signals was plotted against scanning distance; the obtained graphs were used to determine the penetration depth and absorption coefficient.
\end{abstract}

\section{Keywords}

Optical Imaging, Resolution, FT, Cancer Cell, Optical Properties

\section{Introduction}

Skin cancer is the most common form of cancer [1]. Nonmelanoma skin cancers, including basal cell carcinomas (BCCs) and squamous cell carcinomas (SCCs), are more common than all other types of human cancers [2].

Basal cell carcinoma (BCC) is the most prevalent skin cancer among caucasians [3] [4]. BCCs are derived from keratinocytes [5]. The incidence of BCC continues to increase worldwide [6]. It is a multifactorial disease in which excessive sun exposure plays a major pathogenic role [7] [8]. Treatment strategy has changed in the last two decades [9]. Nowadays, a broad variety of imaging techniques are becoming available. Optical imaging, also known as optical tomography, has become an active research field [10]. Several optical imaging techniques 
being investigated include time resolved-optical imaging, frequency-domain optical imaging, optical coherence tomography, optoacoustic tomography and ultrasound-modulated optical (acousto-optical) tomography [11].

Optical coherence tomography is a relatively new noninvasive [12] [13] [14] optical imaging modality for biomedical diagnosis. It is based on low coherence reflectometry which was first developed for telecommunication devices of a high precision in the range of micrometers and lateral introduce to biomedical areas as a method to map the contour and monitor the thickness of retina [15]. The use of optical techniques for diagnostic purpose relies on the capability to measure the optical properties of different tissues. In the fact, a degree of contrast must exist between absorption and scattering coefficients for effective detection of tissue alteration using optical imaging [16].

Recently, extensions of OCT technology, including Doppler flow and polarization sensitive image, have been developed that permit spatially resolved imaging of velocity or birefringence [17].

In ordinary diagnostic, and to understand the origins of disease, material to be examined must be excised from the body and brought to the microscope.

While OCT has potential to go inside the tissue and give us the information from the reflected light, OCT performs imaging by measuring the echo time delay and intensity of backscattered light from internal microstructure in the tissue [18].

The advantages of OCT, as compared to other imaging methods such as CT, NMR and ultrasonic, are that there is no ionizing radiation involved, the method is non invasive, and it is high precision, and lack of need for mechanical contact between instrument and eye, high depth. Doppler imaging is capable of simultaneous imaging and real-time flow measurements [19].

However, there is also a demand for gaining insight into functional parameters of tissue, such as the blood oxygen content. With OCT, we can diagnose small segments of tissue as opposed to most of other imaging modalities that can scan the whole organ; image can be acquired in vivo and in real time without loss of information for unknown sample structure [20]. In addition, it also precludes the need for surgical biopsies and hence avoids discomfort and bleeding of biopsies [21].

Because the velocity of light is extremely high, the echo time delay cannot be measured directly. Instead, it is necessary to use correlation or interferometery techniques [22].

In an OCT system the spectrum of the source is very important as it determines the maximum resolution of the image.

The general requirements of sources of OCT imaging are [23]:

1) Emission in near IR 2) Short coherence length 3) High irradiance

Since OCT has a much higher spatial resolution compared to other imaging modalities, the ability to image internal structures without the need for mechanical probing makes this technique very powerful for medical applications [24]. Its applications in ophthalmology, dermatology, endoscope, cardiology, vascular 
morphology, gastroterology, dentistry, and embryology have been demonstrated by several groups [25]. In this study, optical properties of basal cancer were determined by OCT system.

\section{Materials and Methods}

Laser source (diode 1550) nm, $\leq 4.25 \mathrm{~mW}$, class III) constructed Michelson interferometer, detector, digital oscilloscope (150 MHz), computer, printer, $\mathrm{CCD}$ (LBA-100A) camera.

In this study different cancer cells samples were investigated.

First, laser light incident on the beam splitter, which reflects half of the incident light to the reference mirror which was fixed, and the other half of the incident light was transmitted to the object (the basal cancer) through the concave lens. Figure 1 shows the block diagram of the constructed system.

Then the two beams were reflected or backscattered again to the beam splitter, and interference fringes were obtained after some adjustment done by screws on the fixed mirror. This step was done for all the samples and to scan the sample depth, a micrometer screw was used.

The performed pattern was received by the detector to convert it into voltage, which was displayed on the digital oscilloscope.

Automatic calibration was used to get high accuracy for measurement. Vertical position axis was used to adjust the signal position in the screen, and to display all signals information "Math" button must be pushed, then advanced functions are displayed, and FT can be selected to allow acquired waveforms to be converted into frequency domain traces.

At the last, "Measure" button must be pressed and waveforms information are displayed.

The intensity of that signal was represented (plotted) against scanning distance; the obtained graph was used to determine penetration depth and absorption coefficient. From absorption coefficient all other optical properties can be calculated.

\section{Results and Discution}

The experimental results, which related to the investigation of different cancer samples, were represented in tables, figures and images. Figures 2-5 show the signal recorded by digital oscilloscope.

Figure 2 shows the tissue signal, ones in the center of the figure represent signal before FT, while the lower ones after FT. Information's after FT are: frequency $1.111 \mathrm{kHz}$, peak $240 \mathrm{mv}$, width $0.6 \mathrm{~ms}$, period $0.9 \mathrm{~ms}$ and SNR (backscattered power divided by the noise equivalent bandwidth of the detection) 20 $\mathrm{dB}$.

Figure 3 shows the tissue signal, (a) in normal ordinate before FT, while (b) after FT. Information's displayed on digital oscilloscope for second (BCC) sample are frequency $833.3 \mathrm{~Hz}$, peak $330 \mathrm{mv}$, width $0.5 \mathrm{~ms}$, period $1.2 \mathrm{~ms}$ and SNR $20 \mathrm{~dB}$. 


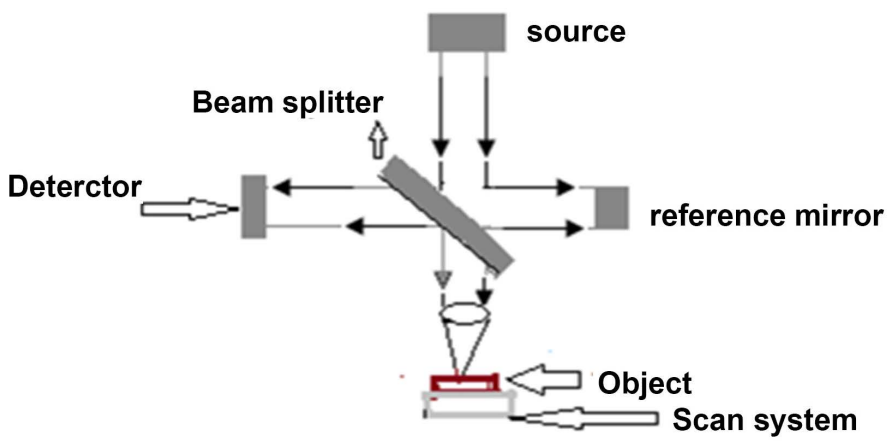

Figure 1. Block diagram of the system.

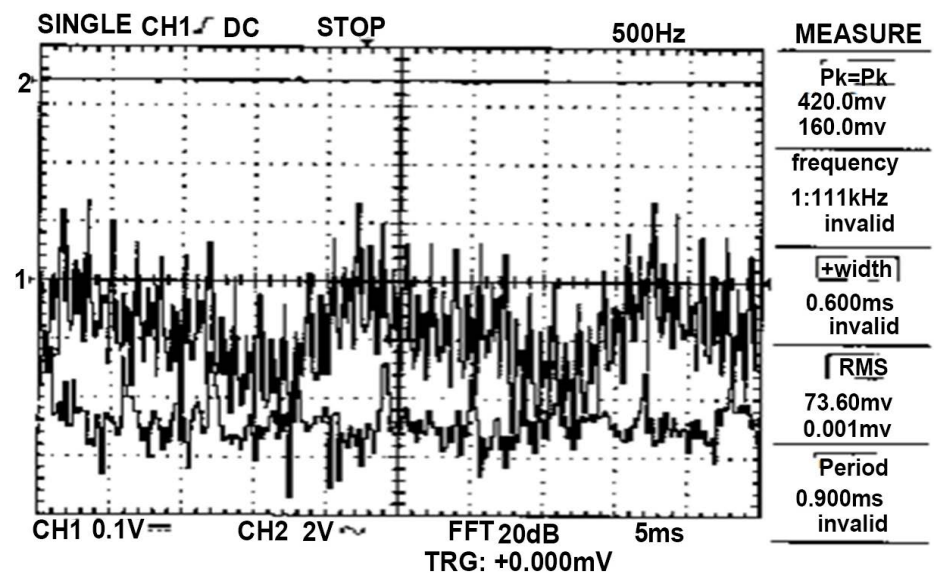

Figure 2. The signal recorded by digital oscilloscope for first (BCC) tissue.

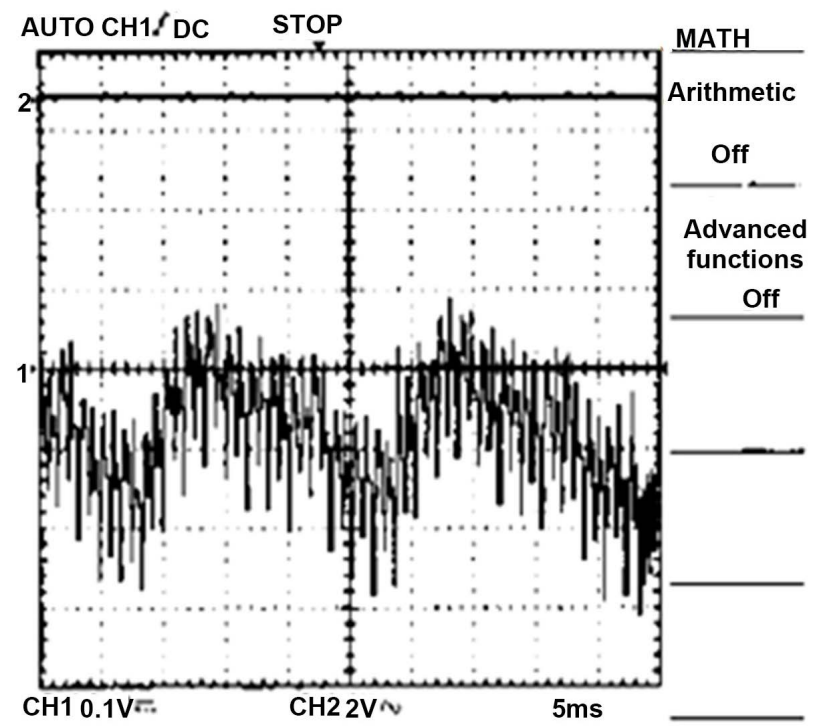

(a)

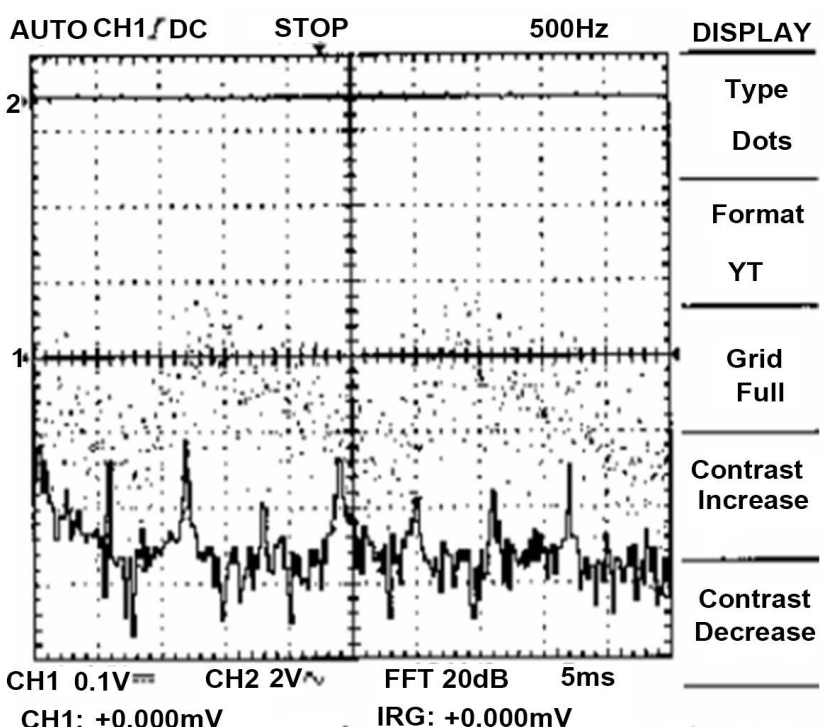

(b)

Figure 3. The signal recorded by digital oscilloscope for second (BCC) tissue. (a) In normal ordinate; (b) In Fourier frequency.

Figure 4 shows the tissue signal, (a) in normal ordinate before FT, while (b) after FT. Information's displayed on digital oscilloscope for third (BCC) sample are frequency $1.25 \mathrm{kHz}$, peak $396 \mathrm{mv}$, width $0.6 \mathrm{~ms}$ and period $0.8 \mathrm{~ms}$. 


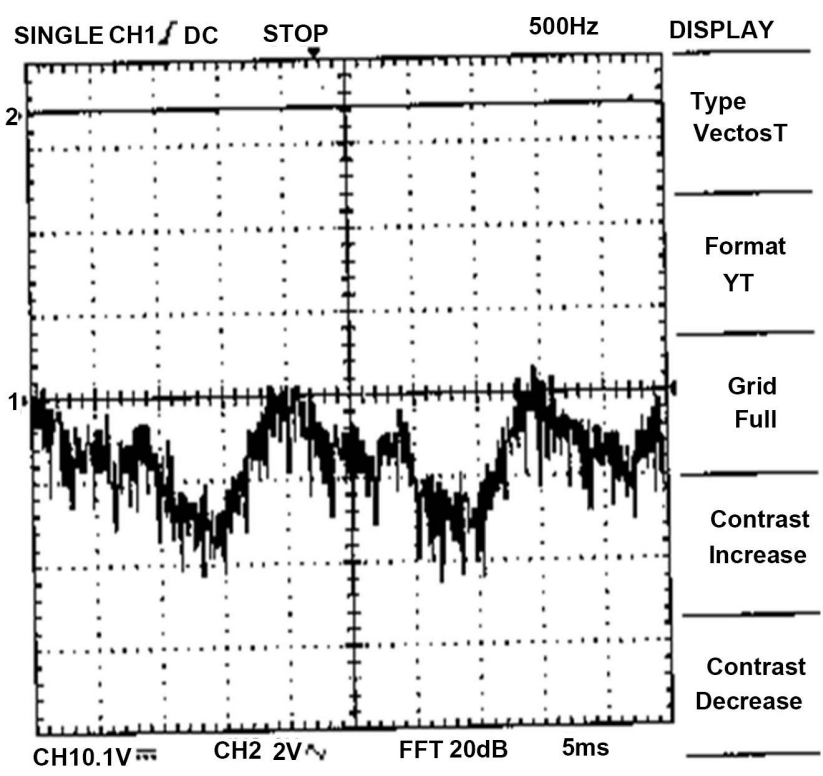

(a)

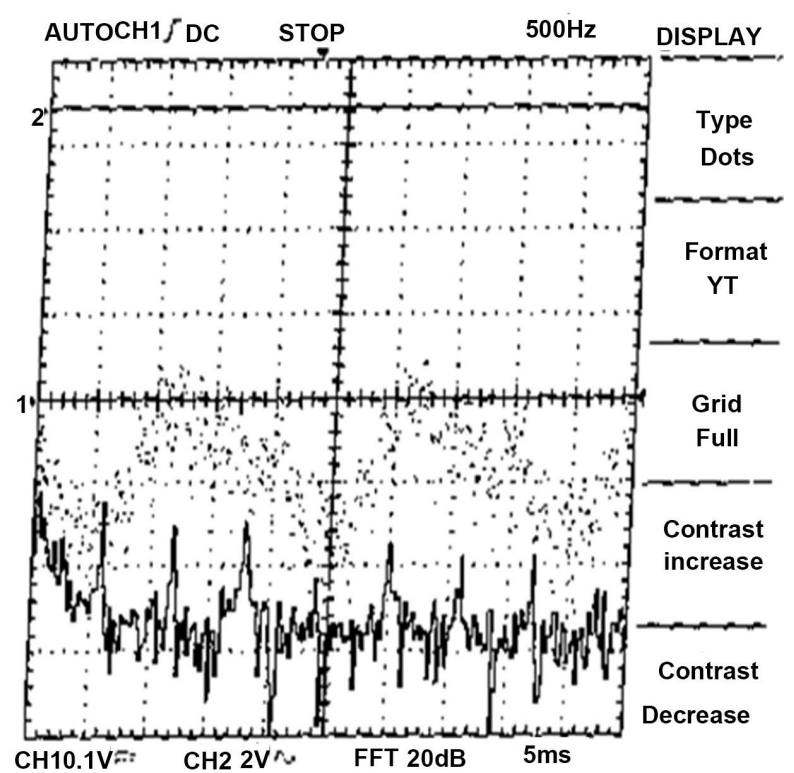

(b)

Figure 4. The signal recorded by digital oscilloscope for third (BCC) tissue. (a) In normal ordinate; (b) In Fourier frequency.

Figure 5 shows the tissue signal, (a) in normal ordinate before FT, while (b) after FT. Information's displayed on digital oscilloscope for fourth (BCC) sample are frequency $833.3 \mathrm{~Hz}$, peak $268 \mathrm{mv}$, width $0.6 \mathrm{~ms}$, period $1.2 \mathrm{~ms}$.

From the signals recorded by digital oscilloscope for studied samples we notice:

Third tissue has the highest peak, while the first one has the lowest one. Also third tissue has a short period $(0.8 \mathrm{~ms})$, which lead to high frequency (Table 1$)$.

From the above results one can see that the optical coherence tomography system (OCTS) can be used to determine the depth resolution and the transverse resolution [26], in longitudinal direction with good performance for different tissues.

According to the above table, longitudinal resolution is higher than transverse resolution for all samples.

Third tissue has the biggest resolution (longitudinal resolution $0.5624 \mu \mathrm{m}$, transverse resolution $0.422 \mu \mathrm{m}$ ) and the minimum for fourth tissue.

From the variation of the intensity with distance, in order to obtain a spectral tomography of the objects [27] [28].

Optical properties can be determined by fitting linear or logarithm function. Figures 6-9 show this variation, while Table 2 illustrates the optical properties for the samples.

There are considerable difference in the optical properties of various types of tissue and even more significant difference in the same tissue at different wavelength [10]. Figures illustrated the lowest backscattered signal for the fourth.

Table 2 shows the highest absorption coefficient for second and fourth tumors, which lead to low penetration depth. 


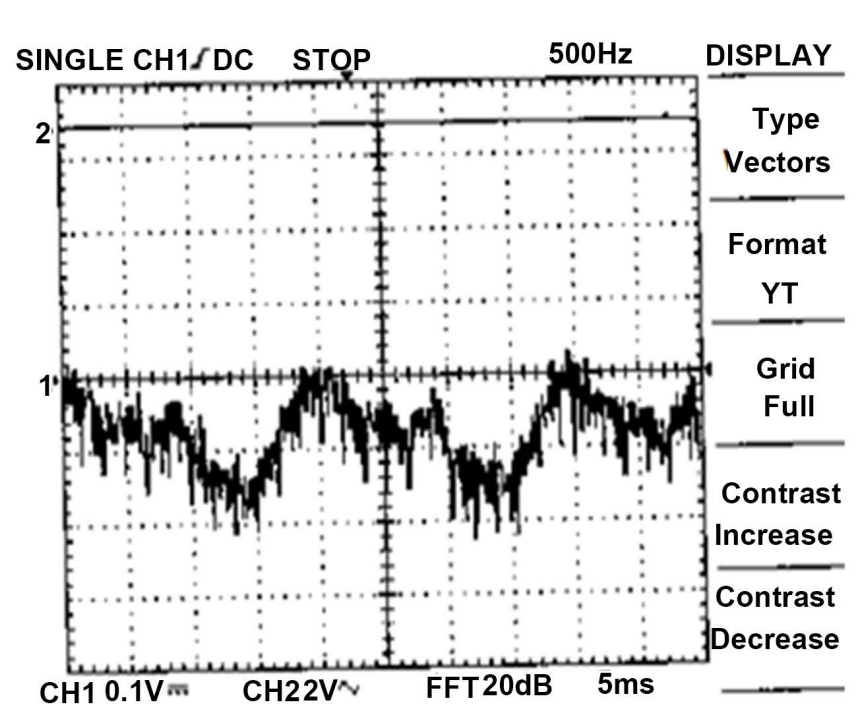

(a)

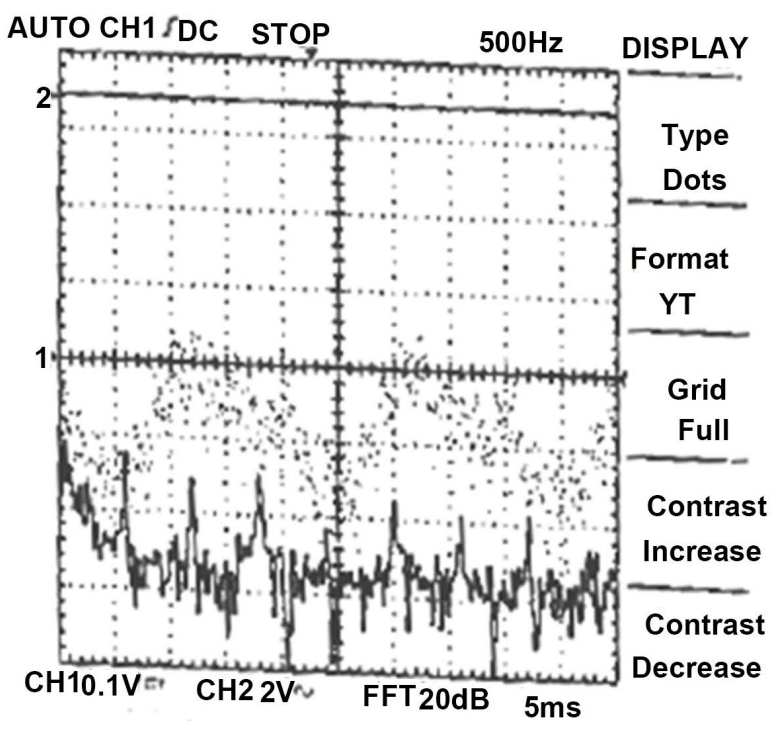

(b)

Figure 5. The signal recorded by digital oscilloscope for fourth (BCC) tissue. (a) In normal ordinate; (b) In Fourier frequency.

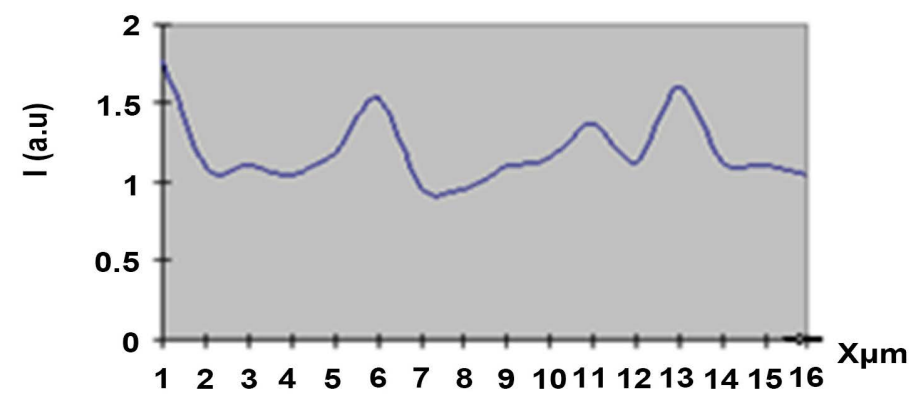

Figure 6. Intensity of the backscattered light as a function of the depth for the First basal cancer.

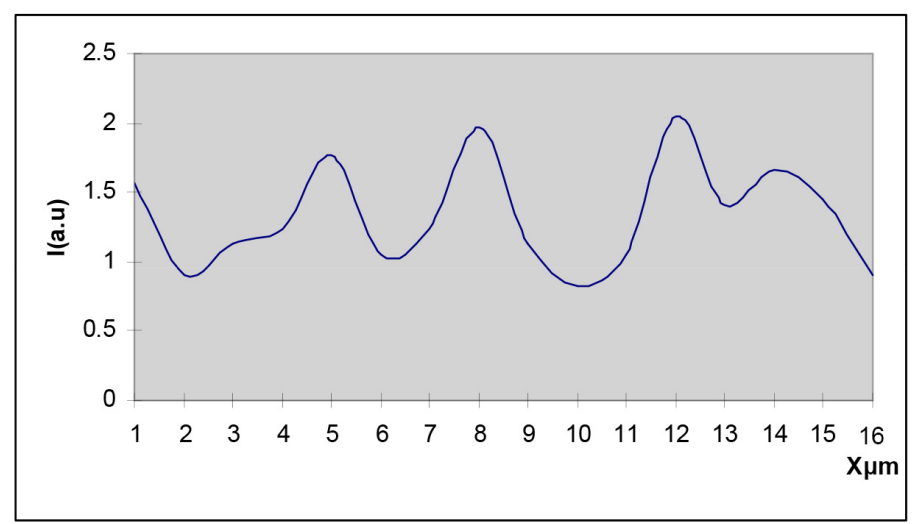

Figure 7. Intensity of the backscattered light as a function of the depth for the second basal cancer.

\section{Conclusions}

1) OCT can be considered as new modality in cancer diagnosing because of its safe considerations and its ability to be applied in vivo. 


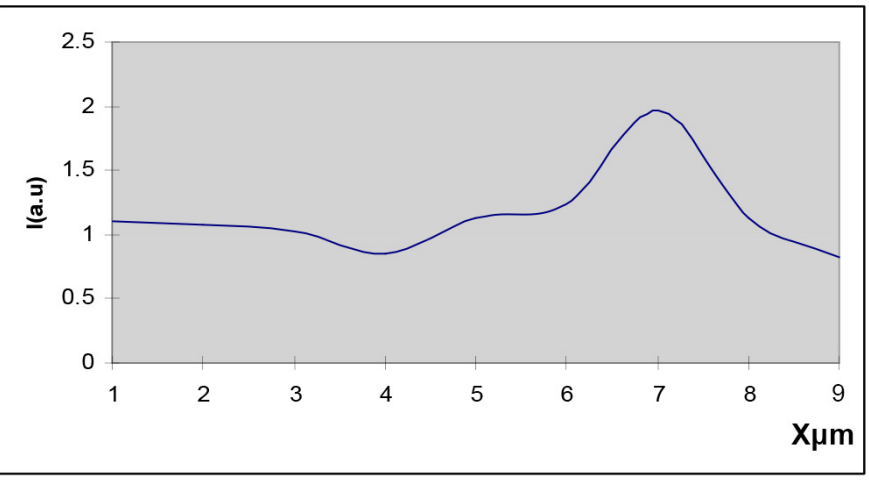

Figure 8. Intensity of the backscattered light as a function of the depth for the Third basal cancer.

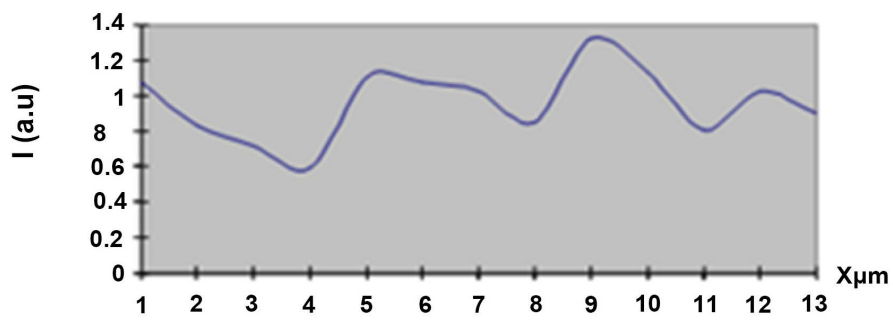

Figure 9. Intensity of the backscattered light as a function of the depth for the Forth basal cancer.

Table 1. List the samples results calculated from Figures 2-5.

\begin{tabular}{ccc}
\hline Samples & $\mathrm{R} \mathrm{R}(\mu \mathrm{m})$ depth resolution & $\Delta \mathrm{LB}(\mu \mathrm{m})$ spatial resolution \\
\hline Basal cancer & 0.37967 & 0.2832 \\
Basal cancer & 0.4398 & 0.3329 \\
Basal cancer & 0.5624 & 0.422 \\
Basal cancer & 0.368 & 0.259 \\
\hline
\end{tabular}

Table 2. Samples optical properties.

(a)

\begin{tabular}{ccccc}
\hline Object type & $\begin{array}{c}\text { Penetration depth } \\
(\mathrm{mm})\end{array}$ & $\begin{array}{c}\text { Absorption } \\
\text { coefficient }\left(\mathrm{mm}^{-1}\right)\end{array}$ & $\begin{array}{c}\text { Attenuation } \\
\text { coefficient }\left(\mathrm{mm}^{-1}\right)\end{array}$ & $\begin{array}{c}\text { Scattering } \\
\text { coefficient }\left(\mathrm{mm}^{-1}\right)\end{array}$ \\
\hline Tissue (1) & 0.062 & 12.375 & 16.129 & 3.754 \\
Tissue (2) & 0.031 & 30.800 & 32.258 & 1.458 \\
Tissue (3) & 0.0605 & 14.000 & 16.529 & 2.529 \\
Tissue (4) & 0.030 & 30.130 & 33.333 & 3.333
\end{tabular}

(b)

\begin{tabular}{cccc}
\hline Object type & $\begin{array}{c}\text { Reduced scattering } \\
\text { coefficient }\left(\mathrm{mm}^{-1}\right)\end{array}$ & $\begin{array}{c}\text { Reduced attenuation } \\
\text { coefficient }\left(\mathrm{mm}^{-1}\right)\end{array}$ & $\begin{array}{c}\text { Reduced penetration } \\
\text { depth }(\mathrm{mm})\end{array}$ \\
\hline Tissue 1 & 7.504 & 19.883 & 0.050294 \\
Tissue 2 & 2.916 & 33.716 & 0.02966 \\
Tissue 3 & 5.058 & 19.058 & 0.05247 \\
Tissue 4 & 6.667 & 36.667 & 0.02727 \\
\hline
\end{tabular}


2) (OCTS) technique can be used to get information of internal structure of the tissue, the contents of the tissue cells and its concentration.

3) The optical properties of different tissues can be determined using OCT.

\section{Recommendations}

Other types of optical tomography techniques can be used to estimate the most efficient one in determination of the optical properties of tissues.

Automatic scanning system can be used to perform good scanning for samples, so that the thickness information of the tissues can be gained with good accuracy.

\section{Acknowledgements}

Deep thanks to Cancer Center and National Institute of Laser Enhanced Science, Cairo University, Egypt.

\section{Conflicts of Interest}

The authors declare no conflicts of interest regarding the publication of this paper.

\section{References}

[1] Alejandro, G.U., Jun, Z., Madeleine, D., Jeong H.C., Victor, G.P. and Lihong, V.W. (2012) In Vivo Diagnosis of Melanoma and Nonmelanoma Skin Cancer Using Oblique Incidence Diffuse Reflectance Spectrometry. American Association for Cancer Research.

[2] Elena, S., Brian, J., John, N. and Anna, N.Y. (2006) Optical Properties of Normal and Cancerous Human Skin in the Visible and Near-Infrared Spectral Range. Journal of Biomedical Optics, 11, 064026. https://doi.org/10.1117/1.2398928

[3] Flohil, S.C., de Vries, E., Neumann, H.A., Coebergh, J.W. and Nijsten, T. (2011) Incidence Prevalence and Future Trends of Primary Basal Cell Carcinoma in the Netherlands. Acta Dermato Venereologica, 91, 24-30.

https://doi.org/10.2340/00015555-1009

[4] Roewert, H.J., Lang, A.B., Stockfleth, E. and Kerl, H. (2007) Epidemiology and Aetiology of Basal Cell Carcinoma. British Journal of Dermatology, 157, 47-51. https://doi.org/10.1111/j.1365-2133.2007.08273.x

[5] Takata, M. and Saida, T. (2005) Early Cancers of the Skin Clinical Histopathological and Molecular Characteristics. International Journal of Clinical Oncology, 10, 391-397. https://link.springer.com/article/10.1007/s10147-005-0532-7 https://doi.org/10.1007/s10147-005-0532-7

[6] Marc, B., Mariano, S., Makiko, M., Alice, M., Gregor, J. and Veronique, D.M. (2016) In Vivo Assessment of Optical Properties of Basal Cell Carcinoma and Differentiation of BCC Subtypes by High-Definition Optical Coherence Tomography. Biomedical Optics Express, 7, 2269-2284.

https://www.osapublishing.org/boe/abstract.cfm https://doi.org/10.1364/BOE.7.002269

[7] Carsin, A.E., Sharp, L. and Comber, H. (2011) Geographical Urban/Rural and Socioeconomic Variations in Nonmelanoma Skin Cancer Incidence a Population-Based 
Study in Ireland. British Journal of Dermatology, 164, 822-829.

https://www.ncbi.nlm.nih.gov/pubmed/21291423

https://doi.org/10.1111/j.1365-2133.2011.10238.x

[8] Sellheyer, K. (2011) Basal Cell Carcinoma Cell of Origin, Cancer Stem Cell Hypothesis and Stem Cell Markers. British Journal of Dermatology, 164, 696-711.

https://www.ncbi.nlm.nih.gov/pubmed/21128907

https://doi.org/10.1111/j.1365-2133.2010.10158.x

[9] Trakatelli, M., Morton, C., Nagore, E., Ulrich, C., Delmarmol, V., Peris, K. and Basset, S.N. (2014) BCC Subcommittee of the Guidelines Committee of the European Dermatology Forum, Update of the European Guidelines for Basal Cell Carcinoma Management. European Journal of Dermatology, 24, 312-329. https://doi.org/10.1684/ejd.2014.2271

[10] Cameron, H.G., Steven, F.B. and Ashely, J.W. (1999) Laser Tissue Interaction, U.S.A.

[11] Lihong, V.W. and Qimin, S. (1999) Sonoluminescence Tomography of Turbid Media. SPIE, Vol. 359, San Jose, California. https://doi.org/10.1684/ejd.2014.2271

[12] Mehreen, A. and Jay, S.D. (2013) Optical Coherence Tomography: Current and Future Applications. US National Library of Medicine National Institutes of Health. Current Opinion in Ophthalmology, 24, 213-221. https://doi.org/10.1097/ICU.0b013e32835f8bf8

[13] David, T. (2018) What Is Optical Coherence Tomography? American Academy of Ophthalmology. https://www.aao.org/eye-health/treatments/what-is-optical-coherence-tomography

[14] Thomsen, J.B., Sander, B., Mogensen, M., Thrane, L., Jørgensen, T.M., Jemec, G.B.E. and Andersen, P.E. (2009) Optical Coherence Tomography Technique and Applications. Springer-Verlag Berlin Heidelberg. https://doi.org/10.1007/978-3-540-68993-5_5

[15] Danielson, B.L. and Whittenberg, C.D. (1987) Guide Wave Reflectometry with Micrometer Resolution. Applied Optics, 26, 2836-2842.

https://www.osapublishing.org/abstract.cfm?uri=ao-26-14-2836 https://doi.org/10.1364/AO.26.002836

[16] Falco, M.D., Lepore, M. and Indovina, P.L. (2000) Difference in Optical Properties of Normal and Tumoral Tissues: A Comparison to Accuracy Limits in Laser Techniques for Optical Imaging. Proceedings of SPIE, 4160.

[17] Laubscher, M., Ducros, M., Karamata, B., Lasser, T. and Salathé, R. (2002) Video-Rate Three-Dimensional Optical Coherence Tomography. Optics Express, 10, 429-435. https://www.osapublishing.org/viewmedia.cfm?uri=oe-10-9-429

[18] Ko, T.H., Witkin, A.J., Fujimoto, J.G., Chan, A., Rogers, A.H., Baumal, C.R., Schuman, J.S., Drexler, W., Reichel, E. and Duker, J.S. (2002) Ultrahigh-Resolution Optical Coherence Tomography of Surgically Closed Macular Holes. Archives of Ophthalmology, 124, 827-836. https://doi.org/10.1001/archopht.124.6.827 https://www.ncbi.nlm.nih.gov/pmc/articles/PMC1937370/

[19] Hitzenberger, C.K., Kuihavy, M., Lexer, F., Baumgartner, A. and Fercher, A.F. (1998) In Vivo Intraocular Ranging by Wavelength Tuning Interferometery. Proceedings of SPIE, 3251, 47-51.

[20] Choi, E., Kim, Y.-J., Kim, M.J., Lee, C. and Lee, B.H. (2003) OCT Resolution Enhancement Using Long Period Fiber Grating and Erbium-Doped Fiber. Proceedings of SPIE, 4956

[21] Riza, N.A. and Yaqoob, Z. (2000) High-Speed No-Moving-Parts Optical Coherence 
Tomography System. Proceedings of SPIE, 4160.

[22] Takada, K., Yokohama, I., Chida, K. and Noda, J. (1987) New Measurement System for Fault Location in Optical Waveguide Devices Based on an Interferometric Technique. Applied Optics, 26, 1603-1606. https://www.ncbi.nlm.nih.gov/pubmed/20454375 https://doi.org/10.1364/AO.26.001603

[23] Fercher, A.F. (1996) Optical Coherence Tomography. Journal of Biomedical Optics, 1, 157-173. https://doi.org/10.1117/12.231361

[24] Dean, P., Dickinson, M.R. and West, D.P. (2003) Optical Coherence Tomography Using a Photorefractive Polymer Composite. Proceedings of SPIE, 4956.

[25] Huang, D., Swanson, E.A., Lin, C.P., Schuman, J.S., Stinson, W.G., Chang, W., Heee, M.R., Flotte, T., Gregory, K., Pulifito, C.A. and Fujimoto, J.G. (1991) Optical Coherence Tomography. Science, 254, 1178-1181.

https://doi.org/10.1126/science.1957169

[26] Fujimoto, J.G. (2001) Optical Coherence Tomography. Applied Physics, 2, 1099-1111.

[27] Leitgeba, R., Wojtkowskib, M., Hizenbergera, C.K., Ferchera, A.F., Stickera, M. and Kowalezykb, A. (2000) Depth Resolved Spectroscopy by Frequency Domain Optical Coherence Tomography. Proceedings of SPIE, 4160, 57-61. https://doi.org/10.1117/12.407608

[28] Hitzenberger, C.K. (1991) Optical Measurement of the Axial Eye Length by Laser Doppler Interferometery. Investigative Ophthalmology \& Visual Science, 32, 616-624. 